\title{
Misunderstandings and Corrections of Innovation and Entrepreneurship Education in Chinese Universities
}

\author{
Chen Jian \\ School of Finance, \\ Guangdong University of Foreign Studies \\ Guangzhou, China \\ 200711642@oamail.gdufs.edu.cn
}

\begin{abstract}
This paper tries to find out the misunderstandings in innovation and entrepreneurship education in Chinese universities and the correction methods thereof. By investigating the development of innovation and entrepreneurship education in China, the paper finds that some misunderstandings and practice errors exist in the development of innovation and entrepreneurship education in Chinese colleges and universities, including that innovation and entrepreneurship education are independent of professional education, innovation and entrepreneurship education are promoted by "one-size-fits-all" policies, the education fails to learn from the failure of creating venture, and "fragmented" practice are carried out in innovation and entrepreneurship education . It concludes some good ways to promote innovation and entrepreneurship education, for example, building a dynamic classification of evaluation system, tolerating "the failure of starting a business " to dig deeper into intrinsic values, and integrating resources and mechanisms both inside and outside the school to build an integrated system of training personnel.
\end{abstract}

Keywords-Innovation and entrepreneurship education; Higher education; Development misunderstandings; Correction suggestions

\section{INTRODUCTION}

In his 2015 government work report, Premier Li Keqiang called for "mass entrepreneurship and innovation" and accelerated the implementation of innovation-driven strategies. The training of innovative entrepreneurship was mentioned as an important strategic at a height never seen before.

At the same time, development time of innovation and entrepreneurship education in colleges and universities in our country is short and the difference between the level of regional economic development and the level of education development is quite large. Some universities have misunderstandings both in concept and operation. Identifying and correcting the misunderstandings in the development of innovation and entrepreneurship education in colleges and universities in our country will help us to further clarify our thinking and speed up the training of innovative and pioneering professionals.

\section{DEVIATION AND DISCRIMINATION IN THE CONCEPT OF INNOVATION AND ENTREPRENEURSHIP EDUCATION}

What is the innovation and entrepreneurship education? The answer to this question concerns the nature of innovation and entrepreneurship education. Due to the short history of innovation and entrepreneurship education in our country, some colleges and universities do not have a good understanding of innovation and entrepreneurship education, and there are misunderstandings in the five major innovations and entrepreneurship education concepts:

\section{A. The innovation and entrepreneurship education is equivalent to employment guidance}

Some colleges and universities limit innovation and entrepreneurship education in senior students who are going to find a job. And they believe that innovation and entrepreneurship education is a matter of expediency to ease the pressure of employment and equivalent to "employment guidance". They are one-sided that employment rate, or entrepreneurial rate were the Evaluation Indicators for the Success of Innovation and Entrepreneurship Education. The thesis of "starting a business "and "quick succession course of boss "reflect such misconceptions. This misconception runs counter to the principle of "facing all" in the "Opinions on Deepening the Reform of Higher Education Institutions for Entrepreneurship and Innovation" promulgated by the State Council and neglects the cultivation of all students' sense of innovation and entrepreneurship. We must abandon it 


\section{B. The innovation and entrepreneurship education is equivalent to the invention of science and technology}

This concept is outcome-oriented, taking innovation and entrepreneurship education as a new production function, and measuring the "output" effect of innovation and entrepreneurship education by means of invention and creation of science and technology. Some colleges and universities with this misconception think that the goal of innovation and entrepreneurship education is to train scientists and inventors, which neglects objectively the cultivation of humanistic qualities such as innovative thinking, entrepreneurial awareness and ability, and also limits innovation and entrepreneurship education to a few elites Students. It's not conducive to innovation and entrepreneurship education in all students indepth. Moreover, this misconception can easily lead to the short-sightedness of innovation and entrepreneurship education and bad attitude to quick success and immediate interest. It mistakenly regards the output of innovation and entrepreneurship education as a material result that can be achieved in a short period of time and ignores the long-term and lagging nature in the achievements of innovation and entrepreneurship education.

\section{The innovation and entrepreneurship education is equivalent to technological innovation}

In the "Internet + " era of knowledge-based economy, entrepreneurship in the field of science and technology explodes with tremendous potential for growth. Star celebrities such as Facebook, Google, Alibaba and Baidu emerged, and start-up stars such as Jack Ma and Robin Li were emerging. Therefore, innovation and entrepreneurship education in the field of science and technology has received all the unprecedented attention and emphasis, and even some colleges and universities mistakenly believe that innovation and entrepreneurship education is science and technology innovation and entrepreneurship. They are keen to set up science parks and organize various science and technology competitions, taking cultivating the potential of science and technology innovation students as main goal of innovation and entrepreneurship education. However, innovation and entrepreneurship education has a broad connotation, including not only the innovation and entrepreneurship in the science and technology industry, but also the ideological innovation, organizational innovation and social entrepreneurship in the social sciences. In Europe and the United States and other countries and regions, innovation and entrepreneurship education in social sciences, especially social entrepreneurship, is considered by higher education as an educational content that is as important as that of science and technology. Equating innovation and entrepreneurship education with science and technology innovation and entrepreneurship can only narrow the connotation of innovation and entrepreneurship education and is not conducive to the development of whole-school innovation and entrepreneurship education for all students, nor is it conducive to the cultivation of innovative and pioneering talents.

\section{The innovation and entrepreneurship education is equivalent to elite education}

Some people think that innovation and entrepreneurship education should focus on cultivating self-employed entrepreneurs and entrepreneurial skills and practical ability, and rely on a variety of entrepreneurial elite classes for innovation and entrepreneurship education. The formation of such misconceptions is not only related to the traditional theory of higher education elite, but also to the eagerness of some colleges and universities. As everyone knows, the elite era of higher education has passed, replaced by era of the popularization of Higher Education which has the rapid increase in the number of university students. Among the huge number of college graduates in our country, there are only a small number of independent entrepreneurs. However, a larger number of college graduates are job seekers, who urgently need innovative thinking and entrepreneurial accomplishments and other humanistic qualities to creatively complete the job tasks in order to deal with the challenge in knowledge economy. Therefore, innovation and entrepreneurship education is not elite education, but a nationwide quality education of innovation, entrepreneurship and literacy. It has the popularity and the whole process, and needs to run through the whole process of talent training.

\section{E. The innovation and entrepreneurship education is independent of professional education}

In practice, some universities do not deeply understand that the purpose of innovation and entrepreneurship education is to cultivate the innovative spirit, entrepreneurial awareness and entrepreneurial ability of all students. They limit innovation and entrepreneurship education to the cultivation of entrepreneurial knowledge and skills, ignoring fostering the spirit of innovation and awareness training in the professional education. In fact, innovation and entrepreneurship education can not be divorced from professional education. Only by deeply integrating innovation and entrepreneurship education with professional education can we find innovative soil and have sustainability. Only in this way can have endogenous support from a wider range of teachers and develop better [1]. 


\section{THE MISUNDERSTANDING AND DISCRIMINATION OF INNOVATION AND ENTREPRENEURSHIP EDUCATION IN PRACTICE}

In practice, most regions and colleges and universities in our country have formed their unique innovation and entrepreneurship education system and mode according to their local conditions, effectively promoting the development of innovation and entrepreneurship education and the training of innovative entrepreneurship talents. However, in some regions and universities, due to the constraints of educational concepts and education system and the urgent task of accomplishing superior tasks, there exists some misunderstandings such as "one-size-fits-all" education for innovation and entrepreneurship, ignoring the learning failure of entrepreneurship and implementing fragmented innovation and entrepreneurship education.

\section{A. "Across the board" to promote innovation and entrepreneurship education, ignoring the diversity of educational subjects}

At present, innovation and entrepreneurship education receives the attention of the whole society. The education department is also actively promoting innovation and entrepreneurship education in all colleges and universities. However, there is the phenomenon of "one size fits all" in the process of formulating assessment standards.

Some colleges and universities, in spite of their own shortage of teachers and educational resources, often rush to open basic courses for entrepreneurship and carry out innovation and entrepreneurship education to all students in order to complete the task of higher education and pass the examination. As a result, they fail to cultivate the talents of innovation and entrepreneurship. In carrying out innovation and entrepreneurship education in some colleges and universities, there is also this phenomenon of "It is not integrated with professional education and is divorced from practice. Teachers' awareness and ability of innovation and entrepreneurship education are deficient, teaching methods are single, and pertinence and effectiveness are not strong enough; The practice platform is short and the guidance is not in place, and the innovation and entrepreneurship education system needs to be perfected."[2]. In addition, from the perspective of the development of foreign innovation and entrepreneurship education, "facing all" is the development direction of innovation and entrepreneurship education, but it also has the characteristics of stage development, the initial stage of quantity growth, the medium stage of organizational transformation and the advanced stage of philosophy infiltration [3]. At the same time, innovation and entrepreneurship education is directed at educating people, which indicates that innovation and entrepreneurship education is a gradual process that can not be done overnight.

\section{B. One-sided emphasis on entrepreneurial success, ignoring the learning from failure of entrepreneurship}

The innovation and entrepreneurship education in some colleges and universities has one-sided emphasis on learning from typical cases of entrepreneurial success, ignoring learning from entrepreneurial failure .Case studies of entrepreneurial failure and related education activities are rare. From a global perspective, high failure rate is an important feature of entrepreneurial activity. According to "Fortune" statistics, the global venture failed as high as $70 \%$. However, foreign educators have found through research that the entrepreneur can learn from the entrepreneurial failure to increase the probability of succeeding entrepreneurship [4]. It can be seen that the imparting experience of entrepreneurial failure is also very important for the innovation and entrepreneurship education. "Entrepreneurial success is often not replicable, and entrepreneurial failures must have common causes." By exploring many common factors and valuable experiences of entrepreneurial failure, we can help learners avoid similar failure factors in starting a business, reduce the failure costs of follow-up entrepreneurs, and improve the entrepreneur's ability to manage negative emotions. They can also change "Winner takes all, loser for Kou "narrow entrepreneurial concept, create a good social atmosphere of entrepreneurship, and encourage more people to join the innovation and entrepreneurship to reflect the value of innovation and entrepreneurship education.

\section{C. "Fragmented" implementation of innovation and entrepreneurship education, ignoring the systematic needs of personnel training system}

In the process of innovation and entrepreneurship education, some students 'working departments such as students' affairs office, the Communist Youth League, career center, etc. sing the "one-man show" and the college teachers rarely participate in. In the meantime, policies for supporting innovation and entrepreneurship in colleges and universities are often scattered in the policy documents of student departments, the Communist Youth League, career centers, research departments, financial departments, graduate students' offices and other departments. The policy design is lack of overall consideration and the inherent inconsistencies, as well as difficult to implement. These phenomena reflect the failure of some colleges and universities to combine organically the innovation and entrepreneurship education with the ongoing process of higher education reform in the process of practicing innovation and entrepreneurship education. Instead, these innovations and entrepreneurship education programs are independent of professional education and personnel training. 


\section{POLICY RECOMMENDATIONS ON RECTIFYING THE MISTAKEN IDEAS OF INNOVATION AND ENTREPRENEURSHIP EDUCATION}

From the above analysis we can see that there are five major misconceptions and three misunderstandings in the development of innovation and entrepreneurship education in Chinese universities. On the one hand, colleges and universities should unify their understanding and abandon the wrong concepts, establish the correct concept of "innovation and entrepreneurship education is innovation-based education for all students, and should be integrated of professional education into the whole process of talent cultivation in colleges and universities". At the same time, in order to solve the misunderstandings in practice, all colleges and universities must take pertinent measures to establish a dynamic evaluation system, explore the intrinsic value of "entrepreneurial failure", and integrate resources to form a comprehensive system of personnel training [5]. Can the innovation and entrepreneurship education be able to develop healthily.

\section{A. Attach importance to the diversity of education subjects, to build a dynamic and innovative evaluation system for innovation and entrepreneurship education.}

In formulating the assessment indicators for innovation and entrepreneurship education in colleges and universities, education authorities should pay attention to the diversification of education subjects, with taking full account of the characteristics of the differences between colleges and universities and the characteristics of phased development of whole-school entrepreneurship education. And it should allow colleges and universities to carry out innovation and pioneering education in a gradual and orderly manner, and carry out classification, dynamic assessment and evaluation on them. If so, it will be helpful to the healthy development of innovation and entrepreneurship education in Colleges and Universities. For example, depending on the type of school, the evaluation of innovation and entrepreneurship education for integrated research universities should focus on the cultivation of students' innovative spirit and entrepreneurial awareness, the cultivation of top-notch creative talents and their contribution to the building of an innovation system at the national level. For ordinary teaching University, the evaluation should focus on entrepreneurship knowledge and ability training and the contribution to the comprehensive development of the region. According to the different stage of education development, colleges and universities with better foundations for innovation and entrepreneurship education should focus on the integrated utilization of resources both inside and outside and the research and practice of educational theories. For colleges and universities with weak foundations, the emphasis should be on popularizing the concept of innovation and entrepreneurship education and on obtaining relevant social resources. For colleges and universities in different regions, the evaluation for the economically developed coastal provinces with private economy should focus on the practice of students' entrepreneurial ability cultivation and entrepreneurship practice, and whether or not they have established a benign mechanism to cultivate the modern service industry. For high-tech industry clusters, universities with rich resources in Beijing, Tianjin and
Shenzhen, the evaluation focuses on the cultivation of students' innovative spirit and entrepreneurial consciousness, and whether a benign mechanism for cultivating technological entrepreneurship is established [6].

\section{B. Tolerance "entrepreneurial failure", in-depth mining of intrinsic value}

On the one hand, colleges and universities should rationally consider the phenomenon of College Students' entrepreneurial failure, and strive to create a campus entrepreneurial atmosphere encouraging innovation and tolerance failure, and take various supporting measures to reduce the failure cost of College Students' economic loss, social cost, psychological cost and so on. For example, colleges and universities may set up specialized psychological counseling rooms for entrepreneurial losers in Chongchuang Space, provide services for failure relief and grief recovery, set up special funds to support and reinvest a certain amount of entrepreneurial loans for undergraduates who have failed in starting a business. On the other hand, colleges and universities should excavate the value of failure to start a business, design reasonable curriculum system, combine the learning of entrepreneurial success and failure experience together, join crowd funding, rapid iteration and lean start-up in campus entrepreneurship training, counseling and training, Grief recovery theory and other methods and practices to reduce the cost of failure, so that the experience of entrepreneurial failure translate into the entrepreneur's ability and motivation for success.

\section{Integration of internal and external resources and mechanisms to build a comprehensive system of training of creative and entrepreneurial talents}

Since the 1980s, British universities set off a wave of transformation from a "research university" to an "entrepreneurial university." British universities such as the Imperial College, Plymouth University, and University of Edinburgh have begun to create a culture of entrepreneurship and entrepreneurship education Courses to carry out entrepreneurial practice. The ideas and practices that British universities advocate the development of modern universities toward "entrepreneurial universities" embody the overall transformation requirements of modern universities in terms of educational philosophy, personnel training, organizational structure and cultural system, which are in line with the synergies of the innovation and entrepreneurship education system. It effectively promoted Britain's innovation ability. In 2015, the reform of innovation and entrepreneurship education is also regarded as one of the important contents of "deepening the comprehensive reform of higher education" in China government report.This shows that the development of innovation and entrepreneurship education is a systematic project and must be supported and coordinated by different departments within the university. Universities must comprehensively reform and innovate in philosophy, organization, teaching, management system and culture, integrate innovation and entrepreneurship education in Professional education and personnel training, and create a comprehensive environment suitable for the development in 
order to promote the vigorous development of innovation and entrepreneurship education.

\section{CONCLUSION}

Through investigation and research, we find that innovation and entrepreneurship education in Chinese universities and colleges has five misconceptions, such as entrepreneurship education is equivalent to vocational guidance, or technological invention and innovation, or technological innovation, or elite education and independent of professional education. At the same time, in practice, there are "one size fits all" to promote innovation and entrepreneurship education, neglecting learning from entrepreneurial failure, fragmented implementation and other wrong practices. Therefore, the department of education should pay attention to diversification of education subject and create a dynamic and classified evaluation system. And the university should be tolerant of business failure and encourage students in learning from it, and integrate internal and external resources and mechanisms in order to promote the development of innovative entrepreneurship education in China.

\section{ACKNOWLEDGMENT}

We are grateful to the Guangdong Province 2015 Education Reform General Project " construction of college students business curriculum under the background of complete credit system- taking business design as an example" , Guangdong Province Philosophy and Social Sciences 12th Five-Year Planning Project discipline co-construction project (GD15XYJ06), and Guangdong Province 2016 Graduate Education Innovation Project "Research and practice on training mode of economics and management degree graduate based on innovation and entrepreneurship-oriented methods" for funding this research.

\section{REFERENCES}

[1] Huang Zhaoxin, Wang Zhiqiang. "On the integration of entrepreneurship education and professional education in Colleges and universities." Educational research, vol12, 2013, pp59-67. (In Chinese)

[2] General Office of the State Council. Opinions of the General Office of the State Council on Deepening the Innovation and Entrepreneurship Education Reform in Colleges and Universities (Guo Ban Fa [2015] No. 36) [EB / OL] http://www.moe.edu.cn/publicfiles/business/htmlfiles / moe / moe_1778 / 201505/187212. html. (In Chinese)

[3] Mei Weihui. "A new perspective on cultivating talents: A theory and practice of school-based entrepreneurship education," Educational Research, vol.6,2012,pp144-149. (In Chinese)

[4] Minniti M, Bygrave W. "A dynamic model of entrepreneurship learning." Entrepreneurship: Theory and Practice. Vol.25,2001,pp5-16.

[5] Liu Haichun, Xie Xiulan, Lou Huidong. "Theory and practice of Innovation and entrepreneurship education in China and foreign countries," Guangdong Higher Education Press, Guangzhou, September 2016. (In Chinese)

[6] Zhang Yan. "Differentiation and strategic thinking of innovation and entrepreneurship education in colleges and universities," China Higher Education, vol.23,2010, pp45-46. (In Chinese) 